University of Wollongong

Research Online

Faculty of Arts - Papers (Archive)

Faculty of Arts, Social Sciences \& Humanities

$1-1-2012$

\title{
How academics can help people make better decisions concerning global poverty
}

Keith J. Horton

University of Wollongong, khorton@uow.edu.au

Follow this and additional works at: https://ro.uow.edu.au/artspapers

Part of the Arts and Humanities Commons, and the Social and Behavioral Sciences Commons

\section{Recommended Citation}

Horton, Keith J., How academics can help people make better decisions concerning global poverty 2012, 265-278.

https://ro.uow.edu.au/artspapers/1928

Research Online is the open access institutional repository for the University of Wollongong. For further information contact the UOW Library: research-pubs@uow.edu.au 


\section{Ethics \& International Affairs}

http://journals.cambridge.org/EIA

Additional services for Ethics \& International Affairs:

Email alerts: $\underline{\text { Click here }}$

Subscriptions: Click here

Commercial reprints: Click here

Terms of use : $\underline{\text { Click here }}$

\section{How Academics Can Help People Make Better Decisions Concerning Global Poverty}

Keith Horton

Ethics \& International Affairs / Volume 26 / Special Issue 02 / June 2012, pp 265 - 278

DOI: 10.1017/S0892679412000329, Published online: 06 July 2012

Link to this article: http://journals.cambridge.org/abstract S0892679412000329

How to cite this article:

Keith Horton (2012). How Academics Can Help People Make Better Decisions Concerning Global Poverty. Ethics \& International Affairs,26, pp 265-278 doi:10.1017/S0892679412000329

Request Permissions : $\underline{\text { Click here }}$ 


\section{How Academics Can Help People Make Better Decisions Concerning Global Poverty}

Keith Horton*

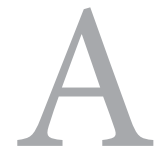

s other contributions to this special issue amply demonstrate, there is a variety of ways in which academics could have a greater impact on global poverty than they do today. In this essay I focus on just one of those ways: by doing more to help people make wise decisions about issues relevant to such poverty. Many different groups of people have to make such decisions, including those who work for certain international organizations, policy-makers and government employees of various kinds, and the global poor themselves. Many of those decisions involve difficult issues that academics generally have more time and other resources than others to study. If academics conduct the right kind of research on those issues, then, and share what they have learned with the relevant decision-makers in accessible ways, those decision-makers should be able to make better decisions. And this in turn should have a positive impact on global poverty. Moreover, given that doing so would only require academics to perform activities that are already taken to be a standard part of their role-conducting research and disseminating what they have learned-this seems one of the most straightforward and least controversial ways in which academics could have a greater impact on global poverty.

But aren't academics already doing this kind of work? The answer to this question will naturally vary depending on the particular issue in question, but in many cases I believe they could do much better. This will not just happen of its own accord, though; it will happen only if enough academics think about the decisions in question from the point of view of the relevant decision-makers, reflect on the

${ }^{*}$ Many thanks to Patricia Illingworth, Rob Reich, and Emma Rooksby for their helpful comments on earlier drafts of this article, and to Luis Cabrera for sound editorial advice.

Ethics \& International Affairs, 26, no. 2 (2012), pp. 265-278.

(C) 2012 Carnegie Council for Ethics in International Affairs

doi:10.1017/So892679412000329 
quality of the input they are currently providing, and where necessary organize themselves in ways that will enable them to improve that input.

In this essay I sketch one way in which such a process of reflection might proceed. I focus for illustrative purposes mainly on one decision one group of decision-makers faces-concerning whether to give money to NGOs working to combat global poverty-highlighting some of the key issues and discussing the academic input on those issues. I argue that such input has been seriously deficient, and suggest some ways in which it might be improved. Building on this discussion, I then formulate two questions that can be applied to any decision concerning global poverty that any set of decision-makers might face, the answers to which would indicate the quality of the input academics are currently providing. I suggest that academics familiar with the relevant literatures ask these questions about such other decisions, and in cases where that input is deficient, and the decision in question is an important one, that they consider organizing themselves in ways that will improve that input. I finish by briefly outlining how the new organization Academics Stand Against Poverty might be able to help them to do so.

\section{The NGO Decision}

Consider, then, one decision the "global rich" (by which I mean all those who are relatively well-off by global standards, not only the "super rich") have to make: whether to give some of their money to nongovernmental organizations (NGOs) working to improve the conditions faced by the global poor. Let us call this the "NGO Decision" for short. ${ }^{1}$ That there is some sort of case for doing so is widely recognized. The global rich are to a greater or lesser extent well-off in absolute terms; the global poor are poor in absolute terms; and the inequality between the two groups is extreme. These facts alone give the global rich strong moral reasons to contribute to tackling global poverty, and giving to NGOs is one obvious way of doing so. ${ }^{2}$ Further, many of the global rich are related to (some of) the global poor in ways that would widely be taken to strengthen such reasons. Some of the global rich belong to the same country or community as some of the global poor, for example, and some belong to countries that deal unjustly with countries and communities in which the global poor live in ways that make it harder for them to escape from poverty-by imposing trade rules rigged in their own favor, for example, or by buying goods that warlords or other illegitimate authorities have effectively stolen from their own people. ${ }^{3}$ 
So there are a number of ethical grounds for thinking that the global rich should give some of their money to NGOs. But there are also a number of reasons to question this conclusion. The reasons most commonly put forward concern worries about the effects of the work such NGOs do. For though there are a number of strong grounds for thinking that such effects might be very good, a number of concerns about NGOs and their work have been raised, ${ }^{4}$ and it is hard to arrive at a credible estimate about those effects. These issues complicate the task of determining whether the global rich should give to NGOs. Even if one puts these concerns aside, moreover, one still faces a number of difficult questions about the moral status of giving to NGOs. Is responding to global poverty primarily a responsibility of governments, and if so what implications does that have for what (if anything) individuals should do? Is tackling global poverty simply one "good cause" among others that the global rich might support or not as they choose, without doing anything that is morally wrong? Or is there something about global poverty in particular that makes contributing to tackling it morally required? If so, what exactly is that? And so on.

This is just a small selection of the difficult questions the NGO Decision requires one to consider. Given how much time and other resources it would take to study all those issues in detail for oneself, it would be helpful if ordinary people (in the current context, those who are not specialists in the relevant issues) could draw on such specialists for guidance. And academics constitute at least one major group of such specialists.

\section{Academic Input into the NGO Decision}

How much help are academics providing with those issues at the moment? Consider first the difficulty of arriving at a credible estimate about the effects. (Henceforth, "the effects" is my shorthand for "the effects of the work NGOs do," by which I mean all the significant identifiable effects, positive and negative.) Of course, it would be unrealistic to expect any very precise estimate about this matter. International aid is a complex business, and any such estimates are therefore likely to be very rough and probabilistic. And for the same reason it would be unrealistic to expect anything approaching certainty that any such estimate is correct. If the global rich literally had no idea at all about how good or bad the effects were, though, they would also have no idea whether they were morally required to give to NGOs, for the answer to the second question depends on the answer to the first. Thus, in order to 
determine whether or not they are morally required to give to NGOs, the global rich do need to form at least some sort of rough estimate about the effects, and have at least some good reason to believe such an estimate is accurate.

At this point, though, one encounters two major problems. The first is that insufficient rigorous research has been conducted on the effects. This problem has been highlighted by many commentators, ${ }^{5}$ and so I will not discuss it here, except to say that certain academics are in a good position to do something about it. Other groups are also in a position to do so, of course, including NGOs themselves. Academics, though, are in general likely to be less subject to pressures to put across a certain view than some other groups of specialists (for example, those who work for NGOs, and certain government employees or advisors), and so their input should be especially trustworthy. In addition, academics may in general find it easier than NGOs to access the (not inconsiderable) funds necessary for such research.

A second problem faced by those seeking to arrive at a credible estimate about the effects of the work of NGOs has received much less attention. Given the lack of rigorous research, the best hope that ordinary people have of arriving at such an estimate is by relying on the advice of those who are at least familiar with what research has been conducted and know how to interpret it, have a good deal of training and experience in the relevant fields, and in other ways are best placed to make such estimates-that is, the aid specialists. ${ }^{6}$ Of course, aid specialists themselves may find it difficult to make such estimates with any confidence, given the lack of rigorous research. Nonetheless, they are surely in a better position to do so than those of us who are not aid specialists, and so it would still be very helpful if they told the global rich-tentatively, perhaps, with whatever qualifications are necessary-what they think. The problem, however, is that (to my knowledge) few if any aid specialists are playing this role. ${ }^{7}$

These problems raise some difficult questions for those seeking to determine whether the global rich should give to NGOs, and if so to which NGOs specifically. Perhaps the key question is whether there is sufficient reason to believe that the effects of at least some NGO activities are good enough to support a moral requirement to give. ${ }^{8}$ Implicit in this question are a number of further questions. How good do the effects need to be in order to support such a requirement? How great a risk of negative effects of what level of seriousness, for example, would rule out such a requirement? How might ordinary people arrive at a credible view about whether the effects (whether of NGO activities in general or of 
particular types of NGO activities) are this good or not? How much reason for confidence that the effects are this good is "sufficient"- - sufficient, that is, for giving to be morally required in practice?

Such questions loom large for anyone wondering whether they should give to NGOs, but one finds very little about them in the academic work on that question, which is found mainly in the discipline of philosophy. It is not that philosophers have neglected the question whether the global rich are morally required to give to international NGOs. On the contrary, there has been quite a lot of discussion about it over several decades. ${ }^{9}$ However, philosophers have tended to discuss that question in a way that takes little if any account of the literature in development studies and related disciplines on NGOs and the effects of their work. And for this reason, at least in part, they have said very little about the questions that this literature raises, such as those sketched here. ${ }^{10}$

Of course, philosophers could hardly have discussed research on the effects of the work NGOs do that (largely) does not exist. They could have highlighted this lack of research, though; raised some of the problems that this leads to with aid specialists and others who might be in a good position to do something about them; suggested reforms aimed at tackling these problems; discussed some of the questions the lack of research and other problems concerning NGO aid raised in the aid literature make urgent; and so on. Given that many of these questions involve closely interlinked normative and empirical issues, moreover, they could also have sought to collaborate with aid specialists on tackling those questions.

One way in which philosophers could do more to help people facing the NGO Decision, then, is by paying more attention to the literature on NGOs and their work, and addressing the questions that such literature raises, ideally at least in part in collaboration with aid specialists. Philosophers and other normative theorists have done a great deal of valuable work on the moral status of giving to NGOs, nonetheless, on the assumption that the effects of at least some of their activities are at least largely positive. ${ }^{11}$ And it is worth noting that there has been a remarkable degree of consensus among these philosophers in favor of the view that the global rich are morally required to give to NGOs, given that assumption. Indeed, this consensus has been so strong that much of the debate in the philosophical literature has focused on how much the global rich are morally required to give, rather than whether they are morally required to give at all. ${ }^{12}$ More generally, there has been a very broad consensus among philosophers that tackling global 
poverty should be given a much higher priority than it normally is, a view that of course has implications far beyond the moral status of giving to NGOs.

Given that different philosophers approach these issues from the perspectives provided by many contrasting moral theories and outlooks; that those theories and outlooks often have divergent implications; that disagreeing with one another is regarded almost as an occupational obligation for philosophers; and that there is generally considered little point in publishing (and often there is no opportunity to publish in philosophy journals) unless one disagrees with others, this degree of consensus is striking indeed. It also means that there are very strong reasons to accept the views in question. And so it would seem to be very important to publicize this consensus in ways that are accessible to the global rich in general as well as to other relevant decision-makers. There has been little if any attempt to do so, however. Currently, one would only find out that there is such a consensus by trawling through the relevant literature in philosophy journals-hardly a realistic option for most people.

\section{Two Questions}

I have focused here on the NGO Decision, which is of course just one decision faced by just one group of people on an issue concerning global poverty. As I said above, though, I have done so mainly in order to illustrate something general: how one might set about assessing the academic input on a decision related to global poverty with the needs of the relevant decision-makers clearly in mind. For one can, of course, ask similar questions about other decisions faced by other groups of people on issues related to global poverty, in order to assess how much help academics are providing with those decisions. Here are two such questions in a general form:

- Have academics conducted sufficient research of appropriate kinds on the issues that most need to be resolved in order for the decision-makers to make the decision in question wisely?

- Have academics shared what they have learned in the ways that are most helpful to those decision-makers?

In the case of the NGO Decision, I have suggested, in effect, that both aid specialists and philosophers have fallen short in relation to both questions. In relation to the first question, aid specialists have failed to conduct sufficient 
rigorous research on the effects of the work NGOs do, while philosophers have failed to conduct their research on whether the global rich are morally required to give to NGOs in a way that takes appropriate account of the research conducted in development studies and other relevant disciplines. These examples illustrate two common ways in which research may fail to be appropriate: by failing to be (sufficiently) rigorous and by failing to take (sufficient) account of work in different relevant disciplines. As for the second question, I have suggested that aid specialists have failed to do enough to share their views about the effects with ordinary people, while philosophers have failed to convey the broad consensus among normative theorists on the strong reasons to give to NGOs and more broadly on the moral priority of tackling global poverty in ways that are accessible to the global rich in general. These examples similarly illustrate two common ways in which academics may fail to share what they have learned in the ways that are most helpful: by failing to convey perceptions of a relevant issue based at least as much on judgment as on more probative grounds, ${ }^{13}$ and by failing to highlight important points of consensus as well as areas of dispute.

If they choose to do so, aid specialists and philosophers could start to fill these gaps. Aid specialists could conduct more rigorous research on the effects, ${ }^{14}$ and in the meantime do more to present their best current understanding of the effects to a general audience. The most significant initiatives aimed at providing substantive guidance to the general public on the effects of NGO aid to date have come not from aid specialists, but rather from others who have in effect stepped in to play the role that aid specialists have neglected. I am thinking of organizations such as GiveWell in the United States and Giving What We Can in the United Kingdom, both of which seek out NGOs or types of aid that there is particularly strong reason to believe have good effects. Both organizations seem to be doing a good job with the resources they have available; it would be even better, though, if aid specialists were to contribute more to such organizations, or to set up their own complementary initiatives, as for many obvious reasons (including some of those listed in endnote 13) such specialists presumably have relevant insights and understanding that others generally lack.

Similarly, philosophers could take more account of the literature on NGOs in other disciplines and tackle some of the main questions that that literature raises, as well as present the broad consensus within the discipline of philosophy on the strong reasons to give to NGOs, and more broadly on the moral priority of tackling global poverty, to the general public. Given that the basic idea here is 
simply that academics should (among other things) do research that is useful, and make sure that their findings are conveyed to those to whom it is useful, it should not be controversial. (It would be controversial if the suggestion was that academics focus only on research that is useful. But of course that is not the suggestion.)

Admittedly, taking such steps may mean going against certain personal and institutional incentives. Tuning in to work in other disciplines can be demanding and time-consuming. Philosophers in particular are trained to focus on points of disagreement, not points of consensus, and are susceptible to the "paralysis of analysis." ${ }^{15}$ Within the academic institution of philosophy, moreover, interdisciplinary work tends to attract less prestige than work in more "central" areas of philosophy, and "applied" work less prestige than more theoretical work. Similarly, writing for a general audience is more likely to reduce one's standing among one's fellow philosophers than to raise it. ${ }^{16}$ More broadly, academic institutions often undervalue the kinds of work that are most useful to "end users" or decision-makers, and so there may be opportunity costs for academics who undertake such work.

Nonetheless, such factors ought not to prevent academics from taking the kind of steps suggested above if there are strong enough reasons to do so. And it appears that there are. One such reason is simply a matter of helpfulness: the NGO Decision is a difficult but important one, and academics would be providing a useful service to the global rich by putting them in a position to make that decision more wisely. (One might also argue that academics have an occupational duty to provide such services; on this, see the piece by Thomas Pogge and Luis Cabrera in this special issue.) And I take it as uncontroversial that certain kinds of input would put the global rich in a better position to make a wise decision. Academic research will not always lead to the right answer, of course, and even when it does and is conveyed to the relevant decision-makers in helpful ways, ${ }^{17}$ those decision-makers will not always act wisely. But still, they will have been placed in a better position to do so, will have a better chance of doing so, and normally more of them will in fact do so.

A second reason for taking the kind of steps suggested above concerns the impact that doing so might have on global poverty. This depends on substantive issues. One such issue is whether there is in fact sufficient reason to believe that the effects of at least certain NGO activities are good enough to support a moral requirement to give to them. If there is, and a suitable group of aid 
specialists (possibly in conjunction with specialists of other relevant kinds) gave authoritative advice to that effect, such activities would be likely to receive more financial support through donations, for as I said above the most common reasons people give for not donating to NGOs tends to be concerns about the effects. ${ }^{18}$ And this would be a very good result, given the assumption that the effects of (at least certain) NGO activities are indeed good enough to support a moral requirement to give to them. ${ }^{19}$ More of the global rich would also probably become involved in campaigns for structural changes related to global poverty, moreover, in part because many NGOs conduct and/or publicize such campaigns. And such action may have even more important consequences in the long run.

It is harder to predict the consequences of a group of philosophers making a serious attempt to publicize the broad consensus in their discipline on the strong moral reasons to give to NGOs to a general audience, in part because nothing like this has ever been attempted before. There are grounds for thinking that doing so might have a significant impact, though. Peter Singer reports that Oxfam America and UNICEF received $\$ 600,000$ more than normal in phone donations during the month after he published an article advocating giving to such organizations in the New York Times. ${ }^{20}$ If one article by one philosopher can have this kind of impact, how great an impact might a collective effort by a group of philosophers and other academics have? Because we have never tried it, we do not know. Similarly, to date there has been no attempt to convey the wide consensus among normative theorists on the moral priority of tackling global poverty more broadly, and so again we do not know what the consequences of such an attempt would be. ${ }^{21}$ If such an attempt were well organized, though, there is surely good reason to think that it would have considerable positive effects.

On certain conditions, then, taking the kind of steps sketched above might have a significant impact on global poverty. This gives those who think those conditions are met a very strong reason to take those steps. Indeed, this reason is so strong that it naturally leads one to wonder why those steps have not already been taken. No doubt a variety of factors are responsible. The kinds of personal and institutional incentives cited above are obviously important, and beyond that many academics simply like to be free to study whatever takes their interest. But another factor, I suspect, is that many academics are simply not used to thinking about their work in the rather instrumental, service-oriented way suggested here-that is, of evaluating that work directly in terms of its usefulness to a certain set of decision-makers. (Academics in certain disciplines are used to thinking in 
this way, but not academics in all disciplines.) And this being so, it just is not a salient issue to them how useful or otherwise their collective input is to such decision-makers. Once the importance of thinking in this way is made clear, though, as well as the potential benefits of improving that input, I suspect that many academics would be sympathetic to the idea of working collectively to improve that input, at least in relation to an issue such as global poverty, given what an ongoing catastrophe such poverty is.

\section{Applying the Approach to Other Decisions}

My suggestion now is that those familiar with the relevant literatures ask the two questions outlined above (Have academics conducted sufficient research of appropriate kinds on the issues that most need to be resolved in order for the decisionmakers to make the decision in question wisely? Have they shared what they have learned in the ways that are most helpful to those decision-makers?) about other important decisions concerning global poverty faced by other decision-makers. This process might be led by the relevant academics themselves, ideally with feedback from other stakeholders, such as academics in other disciplines and, of course, the relevant decision-makers. Alternatively, other stakeholders might lead the process, assessing how useful the academic input on a given decision is and sharing any concerns or suggestions they have with the relevant academics. ${ }^{22}$

Such inquiries will no doubt lead to different conclusions in different cases. In certain cases the answers to the two questions I have outlined may be broadly positive, for in some fields related to global poverty academic research is relatively well attuned to the needs of the relevant decision-makers. ${ }^{23}$ In cases where those answers are not so positive, though, I suggest that academics consider organizing themselves in ways that will enable them to provide more support to the relevant decision-makers, especially in cases where doing so seems likely to have a significant impact on global poverty. I suggest that academics "consider" doing so in part because academic resources are limited (though certainly much underused currently) and so some difficult choices may need to be made about which issues are to be given priority. ${ }^{24}$ One obvious criterion is the likely impact on global poverty of taking the relevant steps. Another factor that will need to be taken into account is how many capable academics there are willing to do the relevant work in the fields in question. If certain fields have significantly fewer academics than are needed, it may be necessary to think more strategically about how to 
build up their numbers over the longer term. For a variety of reasons (including the value of having a diverse range of approaches to poverty-related questions, the fact that many of those questions require detailed country-specific knowledge, and the importance of participation by those who will be more directly affected by any decisions made), it may be particularly important to prioritize building up the capacities of academia in developing countries. ${ }^{25}$

Another major strategic issue concerns the personal and institutional incentives that may discourage academics from the kind of work that is most helpful to those facing important decisions concerning global poverty. As I said above, there are strong reasons for academics not to be too deterred by such factors, at least in a case like global poverty, where there is so much at stake. As Pogge and Cabrera point out in their contribution to this special issue, moreover, the burdens on any particular academics can be reduced if ways can be found to share the relevant tasks fairly. Nevertheless, it would obviously be beneficial if one could smooth the path a little by aligning the incentives that academics face more closely with socially useful ends. As Pogge and Cabrera also point out, in some countries there is increasing pressure on universities and academics to demonstrate their "impact." This pressure is far from being wholly benign, but might nonetheless be turned to positive use by those wishing to encourage academics to provide more helpful input on issues concerning global poverty.

Assessing the academic input on decisions concerning global poverty-and especially doing so in the most efficient and inclusive way-will require a good deal of coordination. Such coordination will ideally be as broadly based as possible among academics and others in various disciplines and in various countries in order to help ensure that all relevant voices are heard, as well as to facilitate the best division of the relevant tasks. The last point I would like to make is that, in conjunction with other organizations and networks, Academics Stand Against Poverty (ASAP) is well positioned to help with this process, through resources such as the Global Poverty Academics Social Network, which aims to support coordination between poverty-focused academics (see academicsstand.org/ projects/the-global-poverty-academic-social-network/), and the World Poverty forum, which could be used to discuss which issues concerning global poverty are in (most) need of more academic input (see academicsstand.org/worldpoverty-forum/). ASAP may also be able to provide a site from which specific research and outreach projects can be launched. ASAP is still at a very early stage, though, and others will no doubt have new ideas about how such an 


\section{organization might best enable academics to provide more helpful input to those}

facing important decisions concerning global poverty, as well as to hasten the eradication of poverty in other ways. So I encourage all those sympathetic to these ends to join ASAP, explore the resources it currently offers, and let us know about any new suggestions you may have.

\section{NOTES}

${ }^{1}$ I take this decision as my main example simply because I know the academic debate about it relatively well-not because I take NGO aid to be more important than official aid, or aid in general to be more significant for global poverty than many other issues.

${ }^{2}$ Not the only way, of course; the global rich might also contribute by taking part in certain campaigns, for example. If one is relatively affluent, though, one ought at least to consider whether one should give some of one's money, whatever else one does. Organizing effective campaigns costs money, moreover, so if one considers such work to be especially important one might use one's donations to support it.

${ }^{3}$ I will no go into details here; I trust these issues will be broadly familiar to most readers of this article.

${ }^{4}$ Again, I will not go into the details here, but for reviews of NGO aid that discuss such concerns, see, e.g., Alan Fowler, "Civil Society, NGDOs and Social Development: Changing the Rules of the Game," Occasional Paper No. 1 (Geneva: UNRISD, 2000); and David Lewis, The Management of Non-Governmental Development Organizations, and ed. (London: Routledge, 2007).

${ }^{5}$ On the lack of rigorous research on the effects of aid in general, see, e.g., William D. Savedoff, Ruth Levine, and Nancy Birdsall, "When Will We Ever Learn? Improving Lives Through Impact Evaluation" (Center for Global Development, 2006); and a number of the papers collected in William Easterly, ed., Reinventing Foreign Aid (Cambridge, Mass.: MIT Press, 2008). On the lack of such research concerning NGO aid in particular, see, e.g., Rick Davies, "Monitoring and Evaluating NGO Achievements" (2001); http://www.mande.co.uk/docs/arnold.htm; and Roger Riddell, Does Foreign Aid Really Work? (Oxford: Oxford University Press, 2007), chaps. 16-19.

6 The category of "aid specialists," as I am using that term, would include both specialists in particular sectors (such as health or finance or agriculture) and people with broad experience across the field of aid and/or development.

7 Naturally all such claims in this essay are similarly "to my knowledge," but I will not repeat this each time. Some aid specialists do address the question of how good or bad the effects are. Those who do so tend to focus mainly on emphasizing the lack of rigorous research, though, and the consequent difficulty of making such an estimate (see, e.g., Fowler, "Civil Society," pp. 11-20; and Riddell, Does Foreign Aid Really Work?). They do not then go on to ask the next questions that arise for potential contributors: "Given this lack of rigorous research, what is the most reasonable assumption to make about the effects? If one cannot make any sort of estimate, no matter how rough or qualified, about the effects of NGO aid as a whole, can one at least make such estimates about certain types of aid or NGOs? Are there, in particular, any NGO activities that one can say with at least some confidence have effects that are good enough?"

${ }^{8}$ Let us say that the effects would "support" a requirement to give if those effects were good enough to imply such a requirement, given certain justified moral premises.

9 A very selective bibliography might include Peter Singer, "Famine, Affluence, and Morality," Philosophy and Public Affairs 1 (1972), pp. 229-43; Peter Singer, The Life You Can Save (New Haven, Conn.: Yale University Press, 2009); William Aiken and Hugh LaFollette, eds., World Hunger and Moral Obligation (Upper Saddle River, N.J.: Prentice Hall, 1977); William Aiken and Hugh LaFollette, eds., World Hunger and Morality (Upper Saddle River, N.J.: Prentice Hall, 1996); Onora O’Neill, Faces of Hunger (London: Allen and Unwin, 1986); Peter Unger, Living High and Letting Die (New York: Oxford University Press, 1996); Deen K. Chatterjee, ed., The Ethics of Assistance: Morality and the Distant Needy (Cambridge: Cambridge University Press, 2004); Garrett Cullity, The Moral Demands of Affluence (Oxford: Oxford University Press, 2004); and Thomas Pogge, World Poverty and Human Rights: Cosmopolitan Responsibilities and Reforms, 2nd ed. (Cambridge, Mass.: Polity, 2008).

${ }^{10}$ Recently some philosophers have started paying more attention to that literature; see, e.g., Garrett Cullity, The Moral Demands of Affluence, esp. chap. 3; Dale Jamieson, "Duties to the Distant: Humanitarian Aid, Development Assistance, and Humanitarian Intervention," Journal of Ethics 9 (2005), pp. 151-70; Leif Wenar in a number of papers, including "The Basic Structure as Object: 
Institutions and Humanitarian Concern," in Daniel Weinstock, ed., Global Justice, Global Institutions (Calgary: University of Calgary Press, 2007), pp. 253-78; and Leif Wenar, "Poverty Is No Pond: Challenges for the Affluent," in Patricia Illingworth, Thomas Pogge, and Leif Wenar, eds., Giving Well: The Ethics of Philanthropy (Oxford: Oxford University Press, 2010). To my knowledge, though, even these philosophers have said very little about the questions just noted in the main text. The nearest thing to an exception I am aware of is some discussion of how ordinary people might try to arrive at a credible estimate of the effects in Wenar's work and in Keith Horton, "Aid Agencies: The Epistemic Question," Journal of Applied Philosophy 28 (2011), pp. 29-43.

${ }^{11}$ I should perhaps add that the great majority of philosophers who have discussed the moral status of giving to NGOs have endorsed some such assumption (as I do myself). Most of those who have argued against such an assumption, moreover, have done so on very thin anecdotal grounds; see, e.g., David Schmidtz, "Islands in a Sea of Obligation: An Essay on the Duty to Rescue," Law and Philosophy 19 (2000), pp. 683-705.

12 In addition to many of the pieces cited in note 10 above, see, e.g., Liam B. Murphy, Moral Demands in Nonideal Theory (Oxford: Oxford University Press, 2000); Barbara Herman, "The Scope of Moral Requirement," Philosophy and Public Affairs 30 (2001), pp. 227-56; and Richard W. Miller, "Beneficence, Duty, and Distance," Philosophy \& Public Affairs 32 (2004), pp. 357-83.

${ }^{13}$ I take it as uncontroversial that one person's view about a certain issue may be more reliable than another's even without such probative grounds, due to such factors as their training and education; their experience; their familiarity with the relevant subject matter; their intelligence, insight, and other intellectual qualities; and so on.

${ }^{14}$ Some have already begun to do so, such as groups that use randomized evaluations, like the Abdul Latif Jameel Poverty Action Lab (www.povertyactionlab.org/) and Innovations for Poverty Action (http:// www.poverty-action.org/). There is of course a debate about what kind of research on the effects counts as rigorous, and whether any such research has general probative value. I do not have space to go into these questions here. (For discussion of randomized evaluations in particular, see, e.g., Angus Deaton, "Instruments of Development: Randomization in the Tropics, and the Search for the Elusive Keys to Economic Development," National Bureau of Economic Research Working Paper, 2009; and Jessica Cohen and William Easterly, eds., What Works in Development? (Washington, D.C.: Brookings Institution Press, 2009). For an NGO perspective on evaluation in general, see Chris Roche, "The Seeming Simplicity of Measurement," in Keith Horton and Chris Roche, eds., Ethical Questions and International NGOs (Dordrecht: Springer, 2010.) For now I will just say that to the extent that there is such a thing as research on the effects that has general probative value, more such research should be conducted; to the extent that there is not, the other task I have highlighted (of sharing views about the effects based at least as much on judgment as on more probative grounds) is the one to focus on. So in either case there is a lot more that aid specialists could do.

15 As David H. Hull puts it, "We seem to find every issue to be so complicated that we cannot possibly do anything but debate some more." David H. Hull, "The Social Responsibility of Professional Societies," Metaphilosophy 33 (2002), pp. 552-65, at p. 555. This article forms part of a symposium, "On the Philosopher as Public Intellectual," which includes a number of papers that are relevant to the issues discussed in this special issue on ASAP.

${ }^{16}$ I comment on such factors especially in relation to philosophy, as that is the discipline I am most familiar with. For some not dissimilar reflections concerning other disciplines (especially development economics), see Devesh Kapur, "Philanthropy, Self-Interest and Accountability: American Universities and Developing Countries," in Illingworth et al., Giving Well. Kapur also makes an important argument in this paper for increasing the accountability of academics who do work that affects people in developing countries.

17 In some circumstances there may also be problems in finding forms of input that are accessible to general audiences without oversimplifying the relevant subject matter in ways that are misleading or falsifying; for a little discussion of this in relation to research on the effects of the work NGOs do, see Keith Horton, “An Appeal to Aid Specialists," Development Policy Review 28 (2010), pp. 27-42, at pp. 36-37.

${ }^{18}$ For a response to some objections to the claim that donations to NGOs are likely to increase if people are given more reason to believe that the effects of their work are good enough, see Horton, "An Appeal," pp. 37-39.

19 Here I am making the plausible assumption that at least some of the relevant activities are scalable; that is, that they can usefully absorb more funds. If, on the other hand, it turns out that no (scalable) NGO activities have effects that are good enough, then it would of course also be helpful to find that out. Those who believe they should contribute to tackling global poverty could then turn their attention to other more suitable forms of action.

${ }^{20}$ See Peter Singer, The Life You Can Save, p. 65. 
21 Academics Stand Against Poverty has recently launched a project that is likely to include something of this kind. This is the Global Poverty Consensus Report, which is aimed at identifying and articulating the overlapping consensus that lies beneath the surface of much academic disagreement on global poverty alleviation in a way that is suitable for feeding into the Millennium Development Goal replacement process; academicsstand.org/projects/the-global-poverty-consensus-report/.

22 This is in effect what I do in "An Appeal to Aid Specialists," made on behalf of both philosophers and ordinary people trying to arrive at a credible estimate about the effects. It is also something GiveWell does in a more general way in its blog, "Suggestions for the Social Sciences." As they put it, "On one hand, we do not have staff with backgrounds in academia. . . . On the other hand, through our work researching charities we do have an unusual amount of experience trying to use academic research to make concrete decisions. In a sense we are a "customer" of academia; think of this as customer feedback"; blog.givewell.org/2011/05/19/suggestions-for-the-social-sciences/[italics and boldface in original].

${ }^{23}$ This is particularly likely to be so in those fields where the relevant decision-makers actually commission some of the research themselves. For one reason or another, though, many important groups of decision-makers, including both the global rich and the global poor in general, and more particular groups among the global rich and the global poor, do not tend to commission such research.

${ }^{24}$ See the other contributions to this special issue (especially Roger Riddell's) for some specific suggestions about priority issues for academics to focus on.

25 This point is made by Kapur in "Philanthropy" (see esp. pp. 280-81); and by Riddell in his contribution to this special issue. 